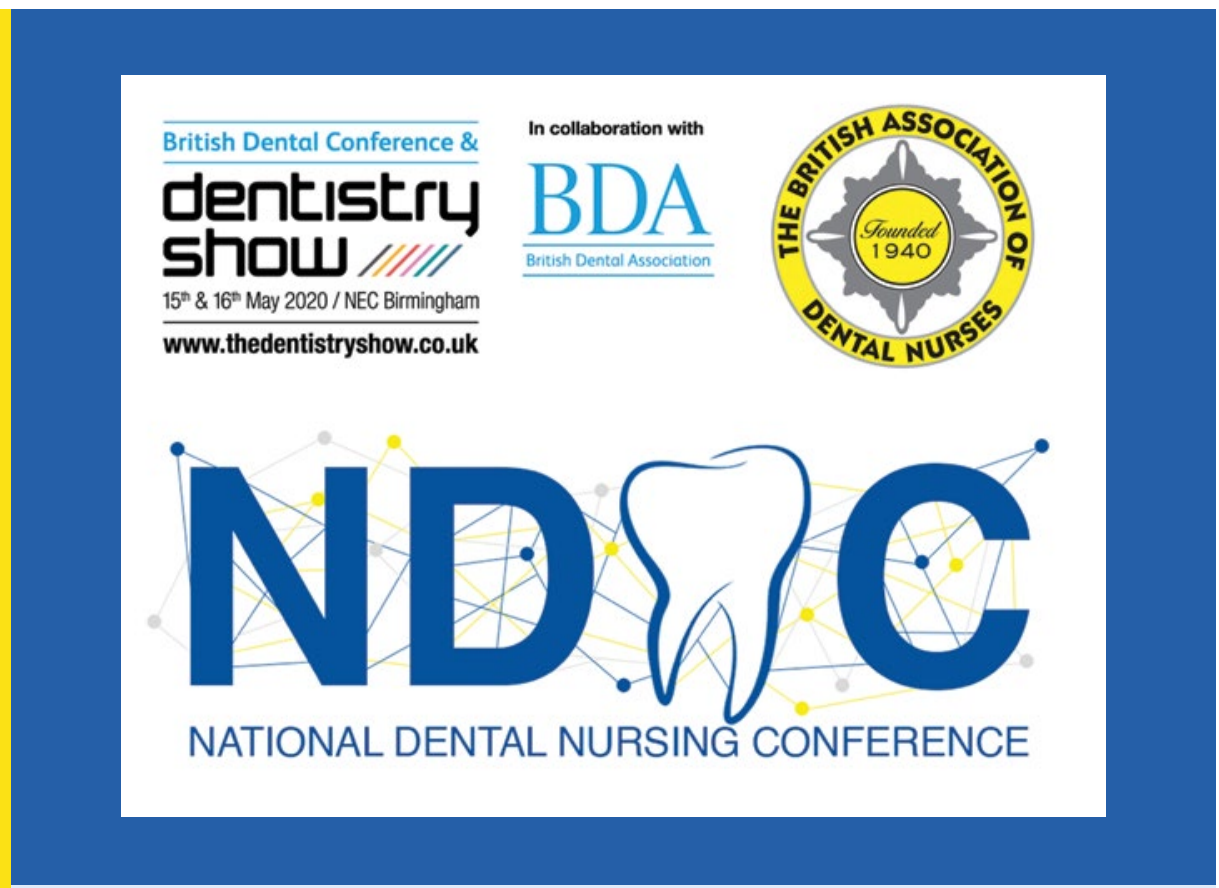

\section{NATIONAL DENTAL NURSING CONFERENCE SET FOR BIRMINGHAM}

Ensuring the relevance and quality of the educational programme, the British Association of Dental Nurses (BADN) will be hosting the National Dental Nursing Conference as part of the British Dental Conference and Dentistry Show 2020.

The British Dental Conference and Dentistry Show 2020, which will be held on 15-16 May at Birmingham NEC, colocated with DTS, will offer an array of learning and networking opportunities for all dental nurses.

The Dental Nurses Forum will be chaired by the BADN and will see leading speakers share their wealth of expertise and advice with delegates, covering everything from patient communication and management to skill development and career progression.

Plus, BADN members will be able to relax in the BADN Lounge between lectures and exhibition browsing on stand L95.

For all this and much more, register for your free delegate pass online. For all the latest information, visit www. thedentistryshow.co.uk, call 02073485270 or email dentistry@closerstillmedia.com.
BSDHT to host educational programme

The British Dental Conference and Dentistry Show 2020 will once again host the dedicated Hygienist \& Therapist Symposium. The British Society of Dental Hygiene and Therapy (BSDHT) will host Friday's programme to ensure its quality and relevance.

Julie Deverick, President of the BSDHT, said: 'The BSDHT has gathered several well-known speakers. They will cover various interesting topics, which are all pertinent to delegates' working lives. We quality assure all the presentations to ensure that the messages being communicated are correct and that they match the proper GDC learning outcomes.

'The conference is a great platform for both members and non-members to come and chat to us and discuss any issues they are experiencing face-to-face. It also provides a chance for professionals to check out new products and ask advice from the representatives, while gaining CPD in all areas of dentistry'

The British Dental Conference and Dentistry Show 2020 will be held on Friday 15 and Saturday 16 May at the Birmingham NEC, co-located with DTS.

For all the latest information, visit www.thedentistryshow.co.uk, call 02073485270 or email dentistry@ closerstillmedia.com.

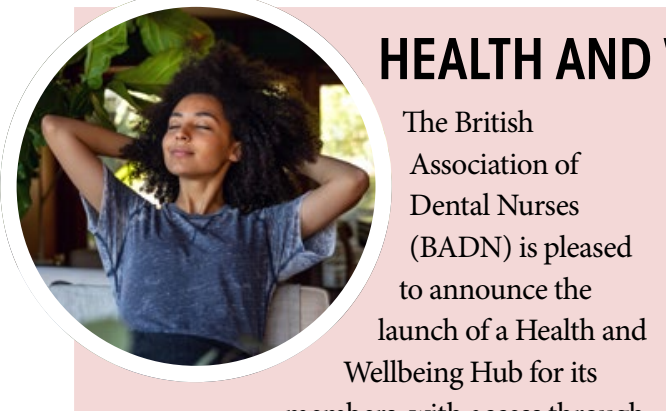

the BADN Benefits platform.

The Health and Wellbeing Hub will offer members articles, tips and practical advice on wellbeing across hot topics including stress management, financial wellbeing and resilience. Every two months the wellbeing hub will launch a new topic and content will continually be refreshed.

\section{WELLBEING HUB LAUNCHED}

Health and wellbeing has never been so important to BADN members and their families. As well as access to the Health and Wellbeing Hub, BADN members also have access to a free legal advice helpline (in January 2020 BADN members used the helpline for nearly 300 minutes of advice) and a 24/7 counselling support line and Health e-Hub mobile application.

BADN Benefits offers a range of discounts and free services to BADN members on a host of everyday purchases. Whether you are looking for cashback on your weekly shopping, discount on your next holiday (either in the UK or abroad), free eye tests or a trip to the cinema BADN benefits will have you covered.
Full Membership of BADN is open to all Registered Dental Nurses, working in all areas of dentistry including education and management, and costs $£ 50 \mathrm{pa}$. Student e-membership is open to all student dental nurses on or awaiting a place on an accredited course leading to a registrable qualification and costs $£ 10$ pa. Associate membership is open to all retired, former and overseas dental nurses. Full Members are also eligible to apply for the special BADN rate indemnity scheme.

For more information on BADN membership and to join, visit www.badn.org. uk. For more information on the National Dental Nursing Conference, Dental Nurse Forum and the Afternoon Tea, contact events@badn.org.uk. 